\title{
HUBUNGAN PENGETAHUAN DENGAN PERSEPSI KEPATUHAN HAND HYGIENE MAHASISWA PROGRAM STUDI NERS UNIVERSITAS ‘AISYIYAH YOGYAKARTA
}

\section{RELATIONSHIP BETWEEN KNOWLEDGE AND PERCEPTION OF HAND HYGIENE COMPLIANCE IN NERS STUDENTS OF UNIVERSITY ‘AISYIYAH YOGYAKARTA}

\author{
Rosiana Nur Imallah* \\ 1*Universitas ‘Aisyiyah Yogyakarta, Jalan Ring Road Barat No. 63 Mlangi Nogotirto Gamping Sleman \\ Yogyakarta, email:roshe_an@yahoo.co.id, Indonesia
}

\begin{abstract}
Background: The fifth goal of patient safety establishing hand hygiene as one effective way to prevent and control Healthcare Associated Infections (HAls). Of the efforts to support the successful implementation of hand hygiene is the obedience, knowledge and perceptions of nurse students who are practicing in hospitals.

Objective: The purpose of this study was to determine the association of knowledge with the perception of hand hygiene compliance of ners students of Aisyiyah University Yogyakarta.

Methods: The study design was descriptive correlational. The sample in this study were 40 nurse students of 'Aisyiyah University Yogyakarta 2017/2018 academic year by purposive sampling technique. The instrument in this study used a questionnaire, then analyzed with Kendal Tau.

Results: The association between knowledge and perception toward hand hygiene compliance was not significant $(p=0.611$ ( $>0.05)$. $p$ value $>0.05$ indicates no relationship between knowledge level and perception of hand hygiene compliance.

Conclusion: There is no association between knowledge and perception of hand hygiene compliance of ners students of 'Aisyiyah University Yogyakarta. The suggestion in this study is to prepare students to behave obediently to do hand hygiene through the learning process in the classroom.
\end{abstract}

Keywords: Hand hygiene, knowledge, perception, student Nurses

\section{PENDAHULUAN}

Healthcare Associated Infections(HAls) merupakan salah satu faktor penyebab meningkatnya angka morbiditas dan mortalitas di rumah sakit, selain itu HAls menyebabkan meningkatnya LOS atau hari rawat inap pasien sehingga merugikan pasien dan meningkatkan biaya perawatan. ${ }^{1}$

Kebijakan tentang sasaran keselamatan pasien kelima menetapkan hand hygiene sebagai salah satu upaya efektif dan sederhana untuk mencegah dan mengendalikan HAls. ${ }^{2}$ Hand Hygiene yang dimaksud yaitu teknik enam langkah dan five moment hand hygiene yang dilakukan secara tepat oleh semua orang yang berada di rumah sakit baik petugas kesehatan, petugas non kesehatan, pengunjung dan mahasiswa yang sedang praktik di rumah sakit. ${ }^{3}$

Upaya yang mendukung keberhasilan pelaksanaan hand hygiene salah satunya adalah kepatuhan mahasiswa perawat yang sedang menjalani praktik di rumah sakit. Mahasiswa perawat yang sedang praktik tersebut sering berinteraksi dengan pasien sehingga memungkinkan untuk lebih berpotensi terpapar agen infeksius. ${ }^{4}$ 
Kepatuhan mahasiswa perawat yang sedang menjalani praktek dipengaruhi oleh pengetahuan dan persepsi tentang hand hygiene. Hasil penelitian yang dilakukan pada mahasiswa perawat yang sedang menjalani praktek di rumah sakit yaitu $36 \%$ mahasiswa belum memahami waktu yang tepat dalam melakukan hand hygiene, dan $18 \%$ berpersepsi bahwa hand hygiene apabila dilakukan terus menerus akan menyebabkan iritasi dan kekeringan pada kulit. $^{5}$

Permasalahan lain yang terjadi yaitu tingkat pengetahuan mahasiswa praktik tentang hand hygine masih dalam kategori rendah (62\%) dan masih ada persepsi yang salah tentang pelaksaanaan hand hygiene (40\%). Hal ini berpengaruh terhadap perilaku kepatuhan mahasiswa dalam hand hygiene. ${ }^{6}$

Program Studi Ners Universitas 'Aisyiyah Yogyakarta berupaya untuk menciptakan mahasiswa yang kompeten, salah satunya terkait perilaku kepatuhan dalam patient safety standar kelima yaitu pencegahan dan pengendalian infeksi. Upaya yang dilakukan yaitu dengan meningkatkan pengetahuan dan kepatuhan dalam pelaksanaan hand hygiene. Tetapi berdasarkan hasil Panum/Pra Ners (persiapan sebelum mahasiswa praktik), pengetahuan dan kemampuan mahasiswa melakukan hand hygiene dengan enam langkah dan five moment belum tepat, yaitu 13 mahasiswa mengatakan bahwa lupa dengan teknik urutan enam langkah hand hygiene. 5 mahasiswa tidak dapat menyebutkan five moment hand hygiene dengan tepat. 25 mahasiswa belum tepat melakukan teknik enam langkah hand hygine.

Penelitian ini dilakukan karena ingin mengetahui pengetahuan dan persepsi mahasiswa tentang hand hygiene karena kedua hal tersebut merupakan faktor penting bagi perilaku kepatuhan melakukan hand hygiene.

Tujuan dalam penelitian ini adalah untuk mengetahui hubungan tingkat pengetahuan dengan persepsi kepatuhan hand hygiene pada mahasiswa Program Studi Ners Universitas ‘ Aisyiyah Yogyakarta.

\section{BAHAN DAN CARA PENELITIAN}

Desain penelitian adalah deskriptif korelasional dengan pendekatan waktu crossectional. Penelitian dilaksanakan pada bulan Juli2018 di Universitas 'Aisyiyah Yogyakarta. Sampel pada penelitian ini adalah 40 mahasiswa yang sedang menempuh Program Profesi Ners Fakultas IImu Kesehatan Universitas 'Aisyiyah Yogyakarta pada tahun Akademik 2017/2018yang diambil dengan teknik purposive sampling.Kriteria inklusi dalam penelitian ini adalah mahasiswa profesi ners TA 2017/2018 yang berstatus aktif, bersedia menjadi responden dan sedang menjalani praktek di area DIY. Kriteria ekslusi yaitu mahasiswa profesi ners TA 2017/2018 yang sedang sakit, sedang izin atau cuti. 
Instrumen yang digunakan dalam penelitian ini adalah kuesioner pengetahuan hand hygiene yang terdiri dari 20 pertanyaan (hasil uji validitas 0,814 dan uji reliabilitas $0,886)$ dan kueisioner persepsi kepatuhan hand hygieneyang terdiri dari 20 pernyataan (hasil uji validitas 0,943 dan uji reliabilitas 0,968).

Proses pengumpulan data dalam penelitian telah mendapatkanethical clearancedengan no surat etik No: 581/KEPUNISA/V/2018dan surat izin penelitian di Universitas 'Aisyiyah Yogyakarta. Teknik pengumpulan data yang digunakan oleh peneliti dengan menggunakan kuesioner. Sebelum pembagian kuesioner terlebih dahulu peneliti menjelaskan maksud dan tujuan penelitian yang akan dilakukan dan meminta persetujuan responden dengan memberikan informed consent kepada responden. Analisis data yang digunakan dalam penelitian ini adalah uji hipotesisKendal Tau.

\section{HASIL DAN PEMBAHASAN}

Tabel 1 karakteristik responden( $n=40)$

\begin{tabular}{ccc}
\hline $\begin{array}{c}\text { Karakteristik } \\
\text { Responden }\end{array}$ & $\begin{array}{c}\text { Frekuensi } \\
(\mathbf{f})\end{array}$ & $\begin{array}{c}\text { Persentase } \\
(\%)\end{array}$ \\
\hline $\begin{array}{ccc}\text { Jenis Kelamin } \\
\text { Laki-laki }\end{array}$ & 8 & \\
Perempuan & 32 & 20 \\
\hline Total & 40 & 100 \\
\hline Usia & & \\
22 tahun & 11 & 27,5 \\
23 tahun & 28 & 70,0 \\
24 tahun & 1 & 2,5 \\
\hline Total & 40 & 100 \\
\hline
\end{tabular}

Sumber: Data Primer 2017
Tabel 1. menunjukkan karakteristik responden berdasarkan jenis kelamin, sebagian besar responden perempuan yaitu sebanyak 32 orang (80\%). Karakteristik responden berdasarkan usia, sebagian besar berusia 23 tahun yaitu sebanyak 28 orang (70\%).

Tabel 2 pengetahuan Hand Hygiene Mahasiswa Program Studi NersUniversitas 'Aisyiyah Yogyakarta

\begin{tabular}{ccc}
\hline $\begin{array}{c}\text { Tingkat } \\
\text { Pengetahuan } \\
\text { Hand }\end{array}$ & $\begin{array}{c}\text { Frekuensi } \\
\text { (f) }\end{array}$ & $\begin{array}{c}\text { Persentase } \\
\text { Hygiene }\end{array}$ \\
\hline Baik & 6 & \\
Cukup & 28 & 15 \\
Kurang & 6 & 15 \\
\hline Total & 40 & 100 \\
\hline
\end{tabular}

Sumber: Data Primer 2017

Tabel 2. menunjukkan sebagian besar responden memiliki tingkat pengetahuan hand hygiene dengan kategori cukup yaitu sebanyak 28 orang (70\%).

Tabel 3 persepsi Kepatuhan Hand HygieneMahasiswa Program Studi Ners Universitas 'Aisyiyah Yogyakarta Kepatuhan Frekuensi Persentasi $\begin{array}{lll}\text { Hand (f) } & \text { (\%) }\end{array}$

Hygiene

\begin{tabular}{lcc}
\hline Patuh & 6 & 15 \\
Cukup Patuh & 27 & 67,5 \\
Kurang Patuh & 7 & 17,5 \\
\hline Total & 40 & 100 \\
\hline
\end{tabular}

Sumber: Data Primer 2017

Tabel 3. menunjukkan sebagian besar responden memiliki persepsi kepatuhan melakukan hand hygiene dengan kategori cukup patuh yaitu sebanyak 27 orang $(67,5 \%)$. 
Tabel 4 hubungan Pengetahuan dengan Persepsi Kepatuhan Hand HygieneMahasiswa Program Studi Ners Universitas'Aisyiyah Yogyakarta $(n=40)$

\begin{tabular}{lcc}
\hline $\begin{array}{l}\text { Kepatuhan } \\
\text { Hand Hygiene }\end{array}$ & $\begin{array}{c}\text { Correlation } \\
\text { coefficient }\end{array}$ & $\mathbf{P}$ (value) \\
\hline $\begin{array}{l}\text { Pengetahuan } \\
\text { Hand hygiene }\end{array}$ & 1,000 & 0,611 \\
$\begin{array}{l}\text { Persepsi } \\
\text { kepatuhan } \\
\text { hand hygiene }\end{array}$ & $-0,76$ & \\
\hline
\end{tabular}

Tabel 4. menunjukkan hubungan pengetahuan dengan persepsi kepatuhan hand hygiene, didapatkan nilai Nilai $\mathrm{P}>0,05$ menunjukkan tidak adanya hubungan tingkat pengetahuan dengan persepsi kepatuhan hand hygiene pada Mahasiswa Program Studi Ners Universitas 'Aisyiyah Yogyakarta.

Hasil analisis penelitian ini menunjukkan bahwa pengetahuan hand hygine mahasiswa perawat yang sedang praktik di RS sebagian besar dalam kategori cukup, hal ini sesuai dengan hasil penelitian terdahulu yang menunjukkan bahwa sebagian besar responden tingkat pengetahuan hand hygiene dalam kategori cukup yaitu 86 (72,9\%). ${ }^{7}$

Pengetahuan merupakan hasil dari tidak tahu menjadi tahu setelah seseorang melakukan penginderaan terhadap suatu objek tertentu. ${ }^{8}$ Pengetahuan mahasiswa perawat tentang hand hygieneyaitu pengetahuan mahasiswa setelah melakukan penginderaan dan melewati proses belajar tentang teknik enam langkah hand hygiene dan five moment hand hygiene. ${ }^{9}$

Mahasiswa ners mendapat pengetahuan hand hygiene dari pendidikan ketika kuliah dan dari media informasi seperti internet, poster, dan video tentang hand hygiene. Hal ini sesuai dengan penelitian yang pernah dilakukan yang menyatakan bahwa pengetahuan mahasiswa tentang hand hygiene didapatkan dari pembelajaran ketika kuliah dan dari media informasi yang berkembang pesat pada saat ini. ${ }^{10}$

Pengetahuan dalam kategori cukup pada mahasiswa perawat tentang hand hygiene ini kemungkinan karena adanya faktor pengalaman yang kurang atau masih minim dalam mengaplikasikan pelaksanaan hand hygiene. Hal ini didukung oleh pendapat yang menyatakan bahwa pengalaman yang didapat seseorang dapat memperluas pengetahuannya. ${ }^{11}$

Pengalaman merupakan sumber pengetahuan, pengalaman juga bisa menjadi suatu cara untuk memperoleh kebenaran pengetahuan. Oleh sebab itu pengalaman pribadi seseorang dapat digunakan sebagai upaya untuk memperoleh pengetahuan. Hal ini dilakukan dengan cara mengulang kembali pengalaman yang diperoleh. ${ }^{12}$

Pengetahuan tentang hand hygieneperlu ditingkatkan oleh mahasiswa karena pengetahuan merupakan faktor yang penting dalam keberhasilan program hand hygiene. $\mathrm{Hal}$ ini didukung oleh hasil penelitian terdahulu yang menyatakan bahwa kurangnya pengetahuan kebersihan tangan akan mengakibatkan perpindahan mikroorganisme dari satu pasien ke pasien yang lain. ${ }^{13}$ 
Hasil analisis peneliti bahwa pengetahuan yang dimiliki mahasiswa tentang hand hygiene perlu suatu upaya untuk meningkatkan dari kategori cukup ke baik Karena hal ini dapat berpengaruh terhadap keberhasilan dari pelaksanaan hand hygiene.

Hasil analisis penelitian ini menunjukkan bahwa persepsi kepatuhanhand hygine mahasiswa perawat yang sedang praktik di RS sebagian besar dalam kategori cukup, hal ini sesuai dengan hasil penelitian terdahulu yang menunjukkan bahwa sebagian besar responden tingkat persepsi kepatuhan hand hygiene dalam kategori cukup lebih banyak daripada responden dengan kategori baik yaitu $52,1 \% .^{14}$

Persepsi merupakan proses yang berkaitan dengan masuknya pesan atau informasi ke dalam otak. ${ }^{15}$ Melalui persepsi ini seseorang mengadakan hubungan dengan lingkungannya baik melalui indera penglihatan, pendengaran, peraba, perasa dan penciuman. ${ }^{16}$

Persepsi mahasiswa perawat tentang hand hygiene dalam kategori cukup kemungkinan karena persepsi yang dimiliki mahasiswa belum mencapai ke tahap persepsi yang positif tentang hand hygiene. Mahasiswa masih berpersepsi bahwa melakukan hand hygiene bukan suatu hal utama yang penting dan mudah dilakukan untuk mencegah HAls.

Persepsi mahasiswa yang belum positif tersebut berpengaruh terhadap keaktifan atau penerimaan mahasiswa dalam melakukan hand hygiene secara patuh. Hal ini sesuai dengan pendapat yang menyatakan bahwapersepsi positif dapatmenggambarkan segala pengetahuan dan tanggapan yang diteruskan dengan upaya pemanfaatannya. Lebih lanjut hal itu akan diteruskan dengan keaktifan untuk menerima dan mendukung obyek yang dipersepsikan. ${ }^{17}$

Hasil analisis peneliti bahwa persepsi yang dimiliki mahasiswa tentang hand hygiene perlu diubah kearah positif sehingga dapat mendukung perilaku kepatuhan hand hygiene.

Hasil analisis penelitian ini menunjukkan tidak ada hubungan pengetahuan dengan persepsi kepatuhan hand hygiene. Hal ini tidak sesuai dengan hasil penelitian terdahulu yang menyatakan bahwa semakin tinggi tingkat pengetahuan seseorang maka persepsi untuk patuh akan semakin baik. ${ }^{18}$

Pengetahuan merupakan faktor penting dalam menentukan perilaku seseorang karena pengetahuan dapat menimbulkan perubahan persepsi. Pengetahuan yang meningkat dapat mengubah persepsi negative menjadi positif. ${ }^{19}$

Pengetahuan pada penelitian ini tidak ada hubungannnya dengan persepsi kepatuhan hand hygiene. Hal ini kemungkinan dapat terjadi karena mahasiswa merasa hand hygiene bukan merupakan target kompetensi yang harus dicapai dalam proses belajar di klinik. 
Sehingga mahasiswa tidak termotivasi untuk melakukan hand hygiene dengan baik. Pada loogbook mahasiswa juga tidak ada target untuk kepatuhan hand hygiene.

Tingkat pengetahuan baik tetapi tidak ada motivasi dalam melakukan sebuah tindakan juga akan berpengaruh terhadap persepsi seseorang untuk patuh. Hal ini sesuai dengan penelitian terdahulu yang menyatakan bahwa motivasi dapat mempengaruhi persepsi seseorang untuk patuh. $^{20}$

Faktor lain yang kemungkinan berhubungan dengan persepsi kepatuhan mahasiswa dalam penelitian ini yaitu pengontrolan perilaku mahasiswa itu sendiri dimana mahasiswa mengikuti budaya perilaku kepatuhan hand hygiene yang ada di RS tempat mahasiswa praktek dan berpersepsi bahwa tidak melakukan hand hygiene dengan tepat selama ini tidak ada dampak negative yang langsung dirasakan oleh mahasiswa.

Persepsi tersebut sesuai dengan teori perubahan perilaku yang menyatakan bahwa perilaku seseorang dapat berubah ke arah yang lebih baik atau patuh dipengaruhi oleh 3 faktor yaitu sikap dalam berperilaku, norma subjektif atau budaya, dan persepsi dalam mengontrol perilaku. $^{21}$ Teori inilah yang menguatkan pendapat bahwa dalam penelitian ini pengetahuan mahasiswa ners tidak ada hubungannya dengan persepsi perilaku kepatuhan hand hygiene.

\section{KESIMPULAN}

Kesimpulan dalam penelitian ini adalah tidak ada hubungan antara pengetahuan dengan persepsi kepatuhan hand hygienepada mahasiswa Program Studi Ners Universitas' Aisyiyah Yogyakarta.Saran dalam penelitian ini adalah menyiapkan mahasiswa untuk berperilaku patuh melakukan hand hygienemelalui proses pembelajaran dikelas. dan melakukan supervisi kepatuhan hand hygiene pada mahasiswa yang sedang menjalani praktik di RS. Saran untuk penelitian selanjutnya yaitu meneliti tentang perilaku praktik kepatuhan hand hygiene.

\section{TERIMA KASIH}

1. Ibu Warsiti,S.Kp.,M.Kep.,Sp.Mat selaku Rektor Universitas 'Aisyiyah Yogyakarta.

2. Ibu Sarwinanti, S.Kep., Ns., M.Kep., Sp.Kep.Mat selaku Ketua LPPM Universitas 'Aisyiyah Yogyakarta.

3. Bapak Ali Imron, S.Sos.,M.Fis. selaku Dekan Fakultas IImu Kesehatan Universitas'Aisyiyah Yogyakarta.

4. Ibu Suratini, S.Kep.,Ns.,M.Kep.,Sp.Kep. Kom. selaku Ketua Program Studi Ners Universitas 'Aisyiyah Yogyakarta.

\section{KEPUSTAKAAN}

1. Jemal, S. Knowledge and Practices of Hand Washing Among Health Professionals in Dubti Referral Hospital, Dubti, Afar, Northeast Ethiopia.Advances in Preventive Medicine.22 November 2018;2018, 1-7. 
2. Provincial Infectious Diseases Advisory Committee.Best practices for hand hygiene in all health care settings. Ontario; Ministry of Health andLong-Term Care Published;2009.

3. World Health Organization. WHO multi modal hand hygiene strategy. Geneva, Switzerland; World Health Organization Press;2009.

4. Zone, L. The Importance of Hand Hygiene in Preventing the Spread of Infection. Journal Community Nursing. 2018; 28;75-78.

5. Abdella, N. M., Tefera, M. A., Eredie, A. E., Landers, T. F., Malefia, Y. D., \& Alene, K. A. Hand Hygiene Compliance and Associated Factors Among Health Care Providers in Gondar University Hospital, Gondar, North West Ethiopia. Biomedical Public Health. 2014; 14; 96.

6. Ningsih, S., Noprianty, R \& Somantri, I. Gambaran Pelaksanaan Kegiatan Kebersihan Tangan oleh Petugas Kesehatan di Rumah Sakit Dustira Cimahi. Jurnal Pendidikan Keperawatan Indonesia. 2018; 3(1); 57.

7. Waltman, L., Schenk, T \&Martin et al. Effect of Student Participation in Hand Hygiene Monitoring on Knowledge and Perception of Infection control practice. Journal of Nursing Education. 10 Desember 2014;50(4); 216-221.

8. Notoatmodjo, S. (2010). Promosi Kesehatan Teori dan Aplikasi. Jakarta: Rineka Cipta; 2010.

9. Prasetyo, $F$ \& Endiyono. Hubungan Pengetahuan dan Sikap Mahasiswa terhadap Kepatuhan Melakukan Cuci Tangan dengan Metode Hand Wash di IGD RSUD Dr. R. Goeteng Taroenadibrata Purbalingga.Urecol. 207;445-450.

10. Anderson, M. E. C., Sargeant, J. M., \& Weese, J. S. Video Observation of Hand Hygiene Practices During Routine Companion Animal Appointments and the Effect of a Poster Intervention on Hand Hygiene Compliance. Biomedical Veterinary Research. 2014; 10; 106.

11. Ott, L \& Irani, V. Evaluating the Effectiveness of Real-Time Feedback on the Bedside Hand Hygiene Behaviors of Nursing Student. Journal of Nursing Education. 2015; 54(5); 286-289.

12. Nair, S. S., Hanumantappa, R \&Gurushantswamy, $\mathrm{H}$ et all. Knowledge, Attitude, and Practice of Hand Hygiene among Medical and Nursing Students at a Tertiary Health Care Centre in Raichur India. ISRN Preventive Medicine. 6 February 2014. 2014; 1-4.

13. Bergellini, A., Ferranti, G \& Santangelo et all. Hand Hygiene Knowledge, Hand Contamination and Practice of Italian Nursing and Medical Student. Epidemiology, Biostatistics and Public Health. 10 Desember 2014; 11 (4).

14. Goldberg, J. Guidline Implementation Hand Hygiene. AORN Jourmal.2017; 105 (2); 203-212.

15. Mcdonald, S. Perception: A concept Analysis. International Journal of Nursing Knowledge. Maret 2014; 23(1); 2-9.

16. Supratman., Pujadari, L \& Mahadian, A. Psikologi Komunikasi. Yogyakarta: Deepublish; 2016.

17. Rios, N.M \& Aguilera, G. Nurses' Perception of Reasons for Persistent Low Rates in Hand Hygiene Compliance. Intensive and Critical Care Nursing. 2017; 42; 17-21.

18. Wulandari, $R$ \& Solikhah, S. pengetahuan dan Penerapan Five Moments Cuci Tangan Perawat di RSUD Sukoharjo. Gaster. 2017;15 (1).

19. Faronbe, J; Adobowale, O; Oluwatoyin et all. Perception Knowledge and Attitude of Nursing Students Towards the Care of Older Patients.International Journal of Africa Nursing Scientics. 2017; 7; 37-42.

20. Hee, O., Kamaludin. N \& Ping, L. Motivation and Job Performance among Nurse in the Private Hospitals in Malaysia. 2016; 9(1); 1-342.

21. Robbins, S.P \& Judge, T.A. Organizational Behavior. New Jersey; Prentice-Hall; 2013. 